\title{
Lyophilized Symbiotic Mitigates Mucositis Induced by 5-Fluorouracil
}

\section{OPEN ACCESS}

Edited by:

Helioswilton Sales-Campos, Universidade Federal de Goiás, Brazil

Reviewed by

Gislane Lelis Vilela de Oliveira São Paulo State University, Brazil Michael Super,

Harvard University, United States

*Correspondence:

Vasco Azevedo vascoariston@gmail.com Fillipe Luiz R. do Carmo

fillipelrc@gmail.com

${ }^{t}$ These authors have contributed equally and share senior authorship.

‡These authors have contributed equally and shared first authorship.

Specialty section: This article was submitted to Inflammation Pharmacology, a section of the journal

Frontiers in Pharmacology

Received: 09 August 2021 Accepted: 01 November 2021 Published: 10 December 2021

Citation:

Savassi B, Cordeiro BF, Silva $S H$, Oliveira ER, Belo G, Figueiroa AG, Alves Queiroz MI, Faria AMC, Alves J, Silva TF da, Campos GM, Esmerino EA, Rocha RS, Freitas $M Q$,

Silva MC, Cruz AG, Vital KD, Fernandes SOA, Cardoso VN, Acurcio LB, Jan G, Le Loir $Y$, Gala-Garcia A, do Carmo FLR and

Azevedo V (2021) Lyophilized Symbiotic Mitigates Mucositis Induced by 5 -Fluorouracil.

Front. Pharmacol. 12:755871. doi: 10.3389/fphar.2021.755871
Bruna Savassi ${ }^{1 \neq}$, Bárbara F. Cordeiro ${ }^{1 \neq}$, Sara H. Silva ${ }^{1}$, Emiliano R. Oliveira ${ }^{1}$, Giovanna Belo ${ }^{1}$, Alessandra Gomes Figueiroa ${ }^{1}$, Maria Izabel Alves Queiroz ${ }^{1}$, Ana Maria Caetano Faria ${ }^{1}$, Juliana Alves ${ }^{1}$, Tales Fernando da Silva ${ }^{1}$, Gabriela Munis Campos ${ }^{1}$, Erick A. Esmerino ${ }^{2}$, Ramon S. Rocha ${ }^{2,3}$, Monica Q. Freitas ${ }^{2}$, Marcia C. Silva ${ }^{3}$, Adriano G. Cruz ${ }^{3}$, Kátia Duarte Vital ${ }^{4}$, Simone O.A. Fernandes ${ }^{4}$, Valbert N. Cardoso ${ }^{4}$, Leonardo Borges Acurcio ${ }^{1}$, Gwénaël Jan ${ }^{5}$, Yves Le Loir ${ }^{5}$, Alfonso Gala-Garcia ${ }^{1,6}$, Fillipe Luiz R. do Carmo ${ }^{1,5{ }^{1 *}}$ and Vasco Azevedo ${ }^{1+*}$

${ }^{1}$ Instituto de Ciências Biológicas, Universidade Federal de Minas Gerais (UFMG), Belo Horizonte, Brazil, ${ }^{2}$ Faculdade de Veterinária, Universidade Federal Fluminense (UFF), Niterói, Brazil, ${ }^{3}$ Departamento de Alimentos, Ciência e Tecnologia Do Rio de Janeiro (IFRJ), Instituto Federal de Educação, Rio de Janeiro, Brazil, ${ }^{4}$ Departamento de Análises Clínicas e Toxicológicas, Universidade Federal de Minas Gerais (UFMG), Belo Horizonte, Brazil, ${ }^{5}$ INRAE, STLO, Institut Agro, Agrocampus Ouest, Rennes, France, ${ }^{6}$ Faculdade de Odontologia, Universidade Federal da Bahia (UFBA), Salvador, Brazil

Mucositis is an adverse effect of cancer chemotherapies using 5-Fluorouracil (5-FU). It is characterized by mucosal inflammation, pain, diarrhea, and weight loss. Some studies reported promising healing effects of probiotic strains, when associated with prebiotics, as adjuvant treatment of mucositis. We developed a lyophilized symbiotic product, containing skimmed milk, supplemented with whey protein isolate (WPI) and with fructooligosaccharides (FOS), and fermented by Lactobacillus casei BL23, Lactiplantibacillus plantarum B7, and Lacticaseibacillus rhamnosus B1. In a mice 5-FU mucositis model, this symbiotic lyophilized formulation was able to reduce weight loss and intestinal permeability. This last was determined in vivo by quantifying blood radioactivity after oral administration of $99 \mathrm{mTc}-$ DTPA. Finally, histological damages caused by 5-FU-induced mucositis were monitored. Consumption of the symbiotic formulation caused a reduced score of inflammation in the duodenum, ileum, and colon. In addition, it decreased levels of pro-inflammatory cytokines IL$1 \beta$, IL-6, LL-17, and TNF- $\alpha$ in the mice ileum. The symbiotic product developed in this work thus represents a promising adjuvant treatment of mucositis.

Keywords: probiotic, chemotherapy, prebiotic, immunomodulant effects, symbiotic

\section{INTRODUCTION}

Mucositis consists of an inflammation, mainly of the small bowel, that affects individuals submitted to cancer chemotherapy treatments, such as 5-Flourouracil (5-FU) (Sonis, 2004). It includes mucosal injury, inflammation, diarrhea, and weight loss. It may lead to mucosal lesions and/or ulcerations throughout the gastrointestinal tract (Rodríguez-Caballero et al., 2012). Mucositis markers include the presence of leukocyte infiltrate in the lamina propria, degenerate enterocytes (Ciorba et al., 2016), accumulation of neutrophils and eosinophils (Antunes et al., 2016), increased degeneration of goblet cells (Stringer, 2013), as well as atrophy of villi (Chang et al., 2012).

There is presently no effective treatment for the prevention or alleviation of symptoms of mucositis. Furthermore, the use of chemotherapeutics causes severe dysbiosis (imbalance in the intestinal microbiota) which in turn worsens intestinal inflammation (van der Velden et al., 2014). In this context, development of alternative or adjuvant treatments is needed. Indeed, the use of probiotics as 
promising candidates for adjuvant treatment of mucositis recently attracted attention (Carvalho RD. et al., 2017). Selected lactic acid bacteria (LAB) strains were reported as probiotics with beneficial effects mediated by different mechanisms of action and offer new perspectives for the development of adapted functional foods (Carvalho RDO. et al., 2017; Eales et al., 2017; Tang et al., 2017). Thus, studies have been carried out to evaluate the potential of such probiotic strains, associated with prebiotics, as possible symbiotic treatments of mucositis (Bastos et al., 2016).

Administration of lactobacilli strains, or of probiotic formulations, can, in pre-clinical models, alleviate experimental mucositis and prevent weight loss, diarrhea, and intestinal damages (Justino et al., 2015; Cordeiro et al., 2018; Do Carmo et al., 2019). As an example, Cordeiro and collaborators showed that the L. casei BL23 strain, when grown in milk supplemented with whey protein isolate, was able to mitigate inflammation in 5-FU-induced mucositis in mice (Cordeiro et al., 2018). Moreover, Galdino et al. (2018) demonstrated that Fructooligosaccharides (FOS), recognized as prebiotic, were able to reduce mucosal damages in such a model (Galdino et al., 2018). Trindade et al. (2018) further reported that the use of the symbiotic Simbioflora ${ }^{\circledR}$ reduced intestinal injury in such a model (Trindade et al., 2018). Products combining probiotics and prebiotics are called symbiotic. They may contain one or more probiotic strain(s) and one or more prebiotic compound(s) (Flesch et al., 2014). They are designed to favor synergy between the combined elements, providing the consumer with the beneficial effects of this association (Flesch et al., 2014). Several studies carried out with symbiotics highlighted effects such as reduction of pro-inflammatory cytokines (Ishikawa et al., 2005), stimulation of the immune system (Raizel et al., 2011), and reduction of intestinal infections and intestinal inflammation (Santos et al., 2015). Futher efforts focused on the quest for new strains, or consortia thereof, to be used as adjuvants in the treatment of mucositis (Picó-Monllor and Mingot-Ascencao, 2019; Shu et al., 2020). In this quest, new candidate strains Lactiplantibacillus plantarum B7 and Lacticaseibacillus rhamnosus D1 may open new perspectives. They were recently shown to prevent infections by Salmonella enterica serovar Typhimurium in $\mathrm{BALB} / \mathrm{c}$ mice and in germ-free-mice, including clinical manifestations such as tissue damages at the level of ileum (Acurcio L. B. et al., 2017, Acurcio et al., 2017 LB; Valente et al., 2019). This protective effect being anti-inflammatory, these strains seem good candidates to be investigated in the context of mucositis.

The aim of this work was thus to develop a symbiotic and lyophilized product, based on milk, supplemented with WPI and FOS, fermented by strains L. casei BL23, L. plantarum B7, and L. rhamnosus $\mathrm{B} 1$, which would be able to reduce the intestinal inflammation, to control the pro-inflammatory immune response, and to decrease intestinal permeability, in a murine model of mucositis induced by 5 -FU.

\section{MATERIALS AND METHODS}

\section{Bacterial Strains and Culture Conditions}

The bacterial strain L. casei BL23 is part of the UMR1219 MICALIS INRA-AgroParisTech collection, Jouy-en-Josas, France. The strains L. plantarum B7 and L. rhamnosus D1 were provided by Professor
Leonardo Acúrcio of Microorganisms and Ecology Laboratory of Physiology, Universidade Federal de Minas Gerais. An aliquot of the bacterial strains L. casei BL23, L. plantarum B7, and L. rhamnosus D1 were first inoculated $(2 \% \mathrm{v} / \mathrm{v})$ in MRS culture medium (deMan, Rogosa, and Sharpe) for $24 \mathrm{~h}$ at $37^{\circ} \mathrm{C}$. Aliquots of bacterial cultures from each strain were then inoculated into $12 \% \mathrm{w} / \mathrm{v}$ low-fat milk medium $(0.1 \% \mathrm{w} / \mathrm{v}$ yeast extract, $2 \% \mathrm{w} / \mathrm{v}$ glucose $)$ supplemented or in the absence of whey protein isolate (WPI) $30 \% \mathrm{w} / \mathrm{v}$. After growth $\left(24 \mathrm{~h} 37^{\circ} \mathrm{C}\right)$, a $1 \mathrm{ml}$ aliquot of each inoculum was removed to assess colony forming unit (CFU) count. Subsequently, $500 \mathrm{ml}$ of each sample along with $500 \mathrm{ml}$ of skimmed milk supplemented with WPI without the presence of bacteria (Matrix), were refrigerated and lyophilized in LH modelo 0601 (LIOMEAL_LBR Liofilização do Brasil). Posteriorly, for 5-FU-induced mucositis mice model, all three strains fermented beverages (L. casei BL23, L. plantarum B7, and L. rhamnosus D1) subjected to lyophilization were homogenized in a 1 : $1: 1$ (g) ratio and, subsequently, added with FOS (NewNutrition ${ }^{\circledR}$ ) in a sterile environment also at a ratio of $1: 1(\mathrm{~g})$. The product composed of three strains lyophilized in a matrix and supplemented with FOS was called Symbiotic.

\section{Physicochemical Analyses and Bioactivity}

The determination of moisture, protein, and fat content were evaluated according to what was previously described (BRASIL, 2006). To determine the moisture content, we oven-dry $5 \mathrm{~g}$ of a sample at $100-105^{\circ} \mathrm{C}$, for $24 \mathrm{~h}$. For protein content quantification and fat levels, we realized the Kjeldahl and Gerber method, respectively (Cordeiro et al., 2021). All results were expressed as $\mathrm{g} / 100 \mathrm{~g}$. The bioactive peptides levels were determinated evaluate the angiotensin I-converting enzyme inhibition (ACEI), antioxidant activity (DPPH), and $\alpha$-amylase and $\alpha$-glucosidase inhibition. For angiotensin I-converting enzyme inhibitory (ACEI) calculate we used the spectrophotometric assay, according to Konrad et al. (2014). For 2,2-diphenyl-1-picrylhydrazyl (DPPH) measurmeant, we used the radical-scavenging method previously described (Lee et al., 2016). Finally, for measurement of a-glucosidase and a-amylase inhibitory activities of lyophilized formulations we used the protocol describe by Grom et al. (2020).

\section{Evaluation of Probiotics Properties of the Formulations in Mucosite Mice Models} Animals

Conventional BALB/c mice (female) between 6 and 8 weeks of age, obtained at Universidade Federal de Minas Gerais (UFMG-Belo Horizonte, Brazil), were used. All mice were kept in a room with temperature-controlled and standard chow diet and ad libitum access to water. This study was approved by the Ethics Committee on Animal Experimentation of the Federal University of Minas Gerais (379/2018).

\section{Experimental Set-Up}

For probiotic treatment, mice were gavaged daily with $500 \mathrm{mg}$ (per day per animal) of dried product resuspended in $\mathrm{PBS}$ pH 7.4 until dissolution $(500 \mu \mathrm{l}$ for maximum final volume) for 13 days. The maximal volume given daily by gavage was set according to the good practice guide to the administration of substances (Diehl 
et al., 2001). To induce the mucositis disease, on day 11, mice of inflamed groups received a single injection of 5-FU (Fauldfluor-Libbs) $(300 \mathrm{mg} / \mathrm{kg}$, intraperitoneally). An injection of saline $(\mathrm{NaCl} 0.9 \%)$ was used in control groups. After $72 \mathrm{~h}$ of this mucositis induction, all mice were euthanized (Carvalho $\mathrm{RD}$. et al., 2017). A longitudinal abdominal incision was performed to remove the intestine for further analyses. The mice were weighed daily. BALB/c mice were divided into five groups. The non-inflamed control (naive) and inflamed control (5-FU) groups received $500 \mu \mathrm{l}$ of PBS pH 7.4, the other three groups received the dose of 5-FU, and were gavaged with $500 \mathrm{mg}$ of samples resuspended in PBS pH 7.4, i.e., the matrix control group was gavaged with the lyophilization matrix (with FOS). The $L$. casei BL23 group and the Symbiotic group were gavaged with probiotic formulations containing in addtion to WPI (lyophilization matrix) and FOS (250 mg per dose), either BL23 ( $\left.10^{9} \mathrm{CFU}\right)$ or the 3 strains $\left(10^{9}\right.$ $\mathrm{CFU}$ ). The maximal volume given daily by gavage was set according to the good practice guide to the administration of substances (Diehl et al., 2001). Each group contained 18 animals.

\section{Histopathological Analysis}

The distal portion of the duodenum, jejunum, and ileum from mice was collected and prepared for histomorphological analysis. For that, tissues were immersed in $4 \%$ buffered formaldehyde solution and then the material was embedded in paraffin, and a $4-\mu \mathrm{m}$ section of each sample was placed on a glass slide and stained with hematoxylin-eosin (HE). The histological score was done by a pathologist, using Soares et al. (2008) protocol. In this protocol, the intensity of the infiltrate of mononuclear and polymorphonuclear cells in the lamina propria of the duodenum, jejunum, and ileum, the presence of ulceration and erosion and changes in mucosal architecture were measured (Soares et al., 2008). For each parameter a classification was given according to the severity of the lesion in the tissues: absent (0), mild (1), moderate (2), and severe (3). For morphometric analysis, 10 images of the ileum of each animal were randomly captured and analyzed using ImageJ software (version 1.8.0). Additional cuts in the paraffinized samples from duodenum, jejunum, and ileum were stained by the Periodic Acid-Schiff (PAS) to determine the number of goblet cells in the tissues (Prisciandaro et al., 2011). Ten random field images of each sample were made using the $40 \mathrm{x}$ objective and the intact goblet cells were counted using ImageJ software (version 1.8.0) and expressed as the number of cells per high-power field (hpf) $\left(40 \mathrm{x}, 108.2 \mu \mathrm{m}^{2}\right)$ (Cordeiro et al., 2018).

\section{Intestinal Permeability}

To assess intestinal permeability, after $72 \mathrm{~h}$ of mucositis induction, a group of animals received $0.1 \mathrm{ml}$ of diethylenetriaminepentaacetate acid (DTPA), labelled with $18.5 \mathrm{MBq}$ of ${ }^{99 \mathrm{~m}}$ technetium, by gavage. Four hours later, the blood was collected, placed in appropriate tubes for radioactive determination and weighing (de Barros et al., 2018). Results were calculated as percentage of dose per $\mathrm{g}$ of blood, by the following equation: $\%$ dose $/ \mathrm{g}$ blood $=(\mathrm{cpm}$ in $\mathrm{g}$ of blood $/ \mathrm{cpm}$ dose of standard) $\times 100 \mathrm{cpm}$ (counts of radioactivity per minute) (Galdino et al., 2018; Do Carmo et al., 2019).

\section{Gene Expression Analysis in the Mice lleum}

Fragments of $1 \mathrm{~cm}$ of ileum were collected and total RNA of samples was extracted using PureLink RNA Mini Kit (Thermo
Fisher Scientific). The extraction protocol was done according to the manufacturer. To digest and remove residual genomic DNA of samples we used DNase I (Invitrogen; Waltham, MA) and Turbo DNA-free Kit (Ambion; Austin, TX). RNA quality was assessed using agarose gel and NanoDrop ${ }^{\circledR}$ ND-1000 (260/ 230 ratio). To prepare the cDNA libraries we used the HighCapacity cDNA Reverse Transcription kit (Applied Biosystems; Foster City, CA). Quantitative PCR (qPCR) was determined using iTaq universal SYBR green supermix (Biorad; Hercules, CA) and gene specific-primers, were selected according to Do Carmo et al. (2019), for zonula occludes 1 and 2 (zo-1 and $z o-2$, respectively), occludin (ocln), claudin-1 $(c \ln -1)$, and claudin-5 $(c \ln -5)$. For housekeeping genes, we encoded $\beta$-actin $(\operatorname{act} \beta)$ and GAPDH $(g a p d h)$. The amplification cycles were performed as described: $95^{\circ} \mathrm{C}$ for $30 \mathrm{~s}$, and $40 \mathrm{cycles}$ of $95^{\circ} \mathrm{C}$ for $15 \mathrm{~s}$ and $60^{\circ} \mathrm{C}$ for $30 \mathrm{~s}$ on ABI PRISM 7900HT Sequence Detection System (Applied Biosystems). Results were expressed as a fold-change of expression levels, using the mean and standard deviations of target expression $\left(2^{-\Delta \Delta \mathrm{Ct}}\right)$.

\section{lleum Tissue Preparation for Cytokine Quantification by ELISA}

Pro- and anti-inflammatory cytokines were quantified by ELISA assay. Briefly, the ileum section of were weighed and homogenized (100 mg tissue/ml buffer) in PBS containing 0.05\% Tween-20 (Sigma-Aldrich, St. Louis, MO), phenylmethylsulfonyl fluoride $0.1 \mathrm{mM}$ (Sigma- Aldrich, St. Louis, MO), benzethonium chloride $0.1 \mathrm{mM}$ (Sigma-Aldrich, St. Louis, MO), EDTA $10 \mathrm{mM}$ (Synth, São Paulo, São Paulo, Brazil), and aprotinin A 20 KIU (Sigma-Aldrich, St. Louis, MO). Suspensions were centrifuged at $3.000 \mathrm{~g}$ for $10 \mathrm{~min} 12$ and the supernatants were collected for dosage of IL- $1 \beta$, IL- 6 , IL- 10, IL17 , TNF- $\alpha$, and INF- $\gamma$ cytokine according to the R and D Systems, Inc. protocols. The absorbance was measured at $492 \mathrm{~nm}$ using a Microplate Reader Model 680 (BIO-RAD). Samples from six animals per group were collected for the ELISA assay, homogenized, and three technical replicates performed.

\section{Statistical Analyses}

Data were performed using one-way ANOVA or two-way ANOVA followed by the Tukey or Sidak post-test. Graphs and statistical analyzes were analized using GraphPad Prism version 9.2.0 (332) for Windows (GraphPad Software, San Diego, CA). All results were presented as the mean \pm standard deviation, and $p<0.05$ was considered as statistically significant.

\section{RESULTS}

\section{Viability of L. casei BL23, L. plantarum B7, and $L$. rhamnosus D1 Strains Submitted to Lyophilization}

The viability of strains $L$. casei BL23, L. plantarum B7, and L. rhamnosus D1, submitted to lyophilization, was measured by CFU couting after rehydration of the product. All three strains, 
TABLE 1 | Proximal composition of fermented milks.

\begin{tabular}{|c|c|c|c|c|c|}
\hline Samples & Moisture & Protein & Fat & Lactose & Ash \\
\hline L. casei BL23 & $88.2 \pm 0.05^{a}$ & $3.52 \pm 0.24^{\mathrm{a}}$ & $1.81 \pm 0.19^{\mathrm{a}}$ & $5.82 \pm 0.16^{a}$ & $0.65 \pm 0.06^{a}$ \\
\hline Symbiotic + FOS & $88.4 \pm 0.02^{a}$ & $3.52 \pm 0.21^{a}$ & $1.82 \pm 0.51^{a}$ & $5.58 \pm 0.70^{\mathrm{a}}$ & $0.68 \pm 0.06^{a}$ \\
\hline
\end{tabular}

*Data are expressed as the mean \pm standard deviation of at least 3 replicates.

${ }^{a-f}$ Different letters in the same column indicate significant differences between samples $(\mathrm{p}<0.05)$.

TABLE 2 | Bioactive compounds of fermented milks.

\begin{tabular}{lcccc}
\hline Samples & DPPH Antioxydant & ACE Inhibition & $\begin{array}{c}\boldsymbol{\alpha} \\
\boldsymbol{\alpha} \\
\text { - amylase Inhibition }\end{array}$ & $\begin{array}{c}\text { - glucosidase Inhibition } \\
\text { Matrix }\end{array}$ \\
L. casei BL23 & $23.7 \pm 0.32^{\mathrm{d}}$ & $23.2 \pm 1.76^{\mathrm{e}}$ & $18.2 \pm 0.31^{\mathrm{e}}$ & $20.5 \pm 0.38^{\mathrm{e}}$ \\
L. casei BL23 + FOS & $23.1 \pm 0.13^{\mathrm{d}}$ & $37.8 \pm 0.24^{\mathrm{d}}$ & $26.7 \pm 0.79^{\mathrm{d}}$ & $32.1 \pm 0.16^{\mathrm{d}}$ \\
Symbiotic & $34.1 \pm 0.34^{\mathrm{c}}$ & $43.1 \pm 0.98^{\mathrm{c}}$ & $39.2 \pm 0.21^{\mathrm{c}}$ & \\
Symbiotic + FOS & $44.3 \pm 0.09^{\mathrm{b}}$ & $58.2 \pm 1.10^{\mathrm{b}}$ & $49.2 \pm 0.45^{\mathrm{b}}$ & \\
& $55.6 \pm 0.28^{\mathrm{a}}$ & $62.1 \pm 0.30^{\mathrm{a}}$ & $62.1 \pm 0.22^{\mathrm{a}}$ &
\end{tabular}

${ }^{*}$ Data are expressed as the mean \pm standard deviation of at least 3 replicates.

${ }^{a-f}$ Different letters in the same column indicate significant differences between samples $(\mathrm{p}<0.05)$. The DDPH, ACE, $\alpha$ - amylase and $\alpha-$ glucosidase was expressed in \%.
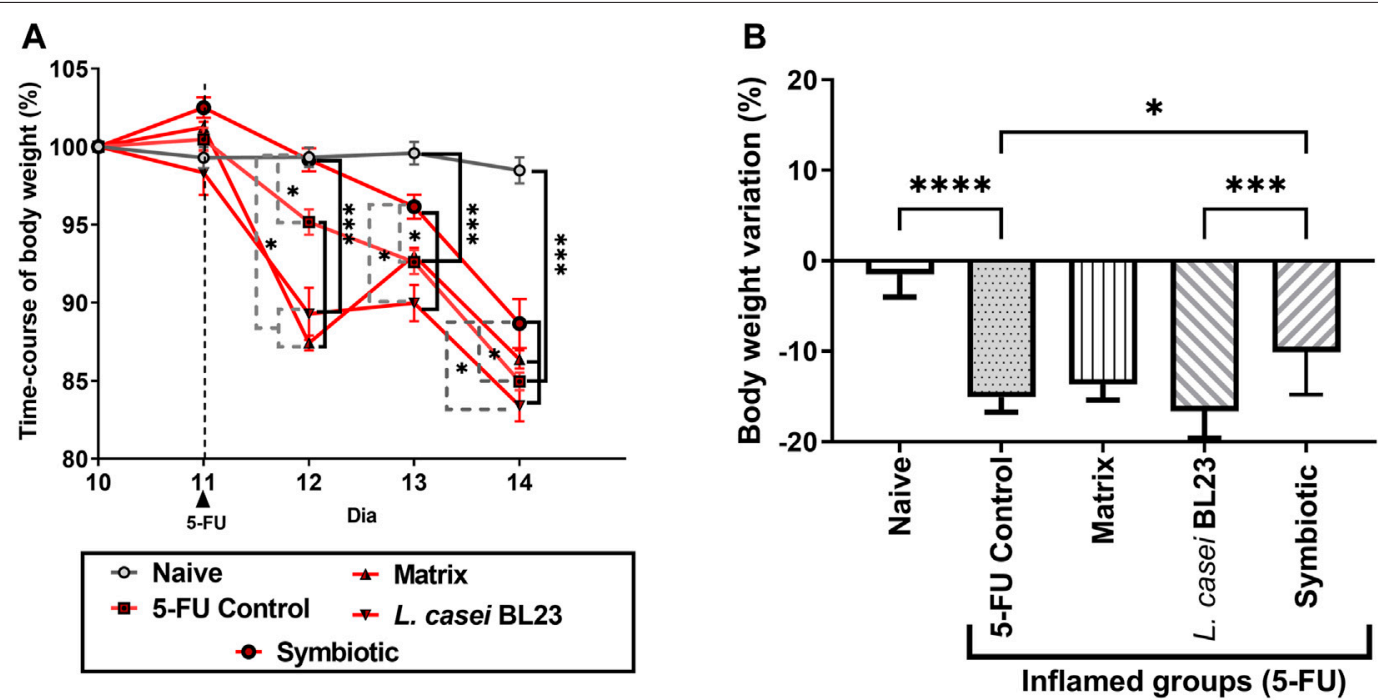

FIGURE 1 | Probiotic lyophilized formulations can interfere with weight loss in mice with 5-FU-induced mucositis. Variation in body weight of mice (in percentage) over the last 5 experimental days (A) of animals that were gavaged with: PBS pH 7.4 (Naive group and 5-FU inflamed control group); 12\% skimmed milk supplemented with 30\% WPI and Fructooligosaccharide (Matrix); a formulation containing L. casei BL23, a formulation containing the mix of probiotics (Symbiotic). (B) Body weight variation (in percentage) observed after the last experimental day (14th day) considering the 10th experimental day as initial weight (100\%). Animals gavaged with PBS was used as experimental controls. The one-way or two-way ANOVA test, followed by Sidak or Tukey post-test was used for the multiple comparisons between groups $(n=6-9)$. Asterisks represent statistically significant differences as follows: ${ }^{\star} p<0.05 ;{ }^{\star \star} p<0.01 ;{ }^{\star \star *} p<0.001 ;{ }^{* \star \star} p<0.0001$.

cultivated in the formulations with or without WPI, reached populations greater than $2 \times 10^{9} \mathrm{CFU} / \mathrm{g}$. The population of $L$. casei BL23 was $4 \times 10^{9} \mathrm{CFU} / \mathrm{g}$ and $3 \times 10^{9} \mathrm{CFU} / \mathrm{g}$ (before and after lyophilization, respectively). That of $L$. plantarum $\mathrm{B} 7$ was 3.3 $\times 10^{9} \mathrm{CFU} / \mathrm{g}$ and $2.3 \times 10^{9} \mathrm{CFU} / \mathrm{g}$ (before and after lyophilization, respectively). Similar results were observed with L. rhamnosus D1: $4.9 \times 10^{9} \mathrm{CFU} / \mathrm{g}$ and $2.5 \times 10^{9} \mathrm{CFU} / \mathrm{g}$ (before and after lyophilization, respectively).

\section{Proximate Composition and Bioactivity Compounds}

The Matrix formulation, containing WPI and FOS, was used as a control in the analysis of proximate composition and bioactivity compounds. The proximal composition of the probiotic formulations is described in Table 1. Analyzed parameters were moisture, proteins, lipids, lactose, and ash. It was not possible to find significant differences between the fermented 
samples (L. casei BL23 or Symbiotic in the presence or absence of FOS). However, there was a significant difference between the Matrix control and the other formulations.

Table 2 shows the bioactive compounds in the formulations proposed in this study. Regarding the analyzed bioactives: antioxidant potential (DPPH), inhibition of the enzyme converting angiotensin ACE, inhibition of a-amylase, and inhibition of $a-$ glucosidase, the Symbiotic lyophilized product showed the highest values with significant differences $(p<0.05)$, when compared to other lyophilized product. Moreover, there was a significant difference $(p<0.05)$ in the bioactives levels of the Symbiotic with FOS, with higher values, when compared to the Symbiotic formulation in the absence of FOS.

\section{Symbiotic Reduces the Weight Loss in Mice with Mucositis}

Figure 1 shows the time-course of mice body weight monitoring during the last five experimental days (10th to 14 th day). During the pre-treatment period, prior to mucositis induction (1st to 10th day), there was no significant difference (data not shown) between the control groups (Naive and 5-FU) and the experimental groups (Matrix, L. casei BL23, Symbiotic). After the induction of mucositis, Figure 1A shows that the animals receiving the dose of $300 \mathrm{mg} / \mathrm{kg}$ of the chemotherapy 5-FU began to lose weight on the 12th experimental day, while bodyweight of control naïve mice remained constant. Moreover, all groups receiving 5-FU showed significant weight loss, when compared to the Naive group. The group of animals that received the Symbiotic treatment showed a significant difference $(p<0.05)$ in the daily variation of weight loss on the 12th and 13th experimental days. The peak of weight loss occurred on the 13th and 14th day of the experiment (Figure 1A). 5-FU administration, as shown in Figure 1B, induced weight loss in all experimental groups. However, the Symbiotic treatment significantly reduced $(p<0.05)$ the loss, compared to $5-\mathrm{FU}$ (inflamed control group) and to L. casei BL23. We also observed a small weight loss in the Naive group without inflammation.

\section{Symbiotic Improves Mucosal Preservation in Small Intestine of the Inflamed Mice}

After euthanasia, the duodenal, jejunal, and ileal sections of the animals were collected and stained with $\mathrm{HE}$ and submitted to histological analysis to evaluate mucositis severity. Figures 2A-C show representative photos of the duodenum, jejunum, and ileum

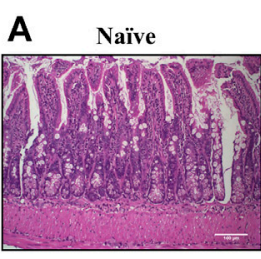

B

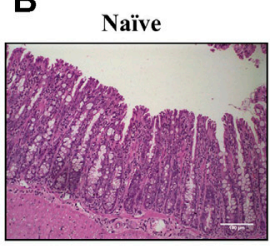

C

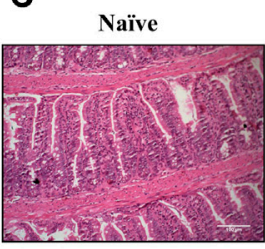

5-FU Control
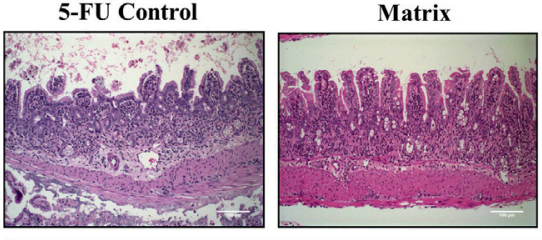

Duodenum section of inflamed groups (5-FU-induced Mucositis)
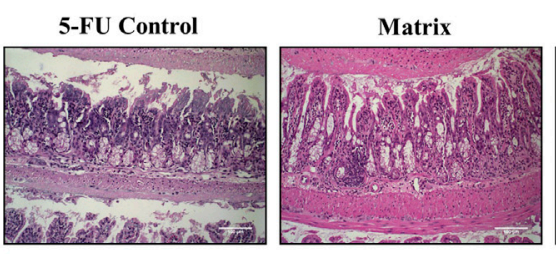

L. Casei BL23
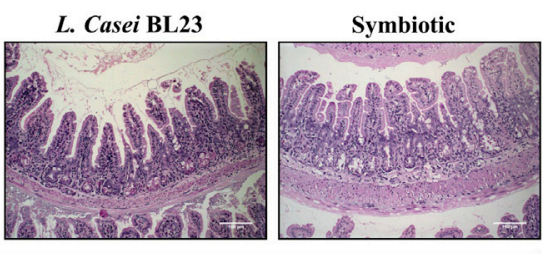

Jejunum section of inflamed groups (5-FU-induced Mucositis)

5-FU Control

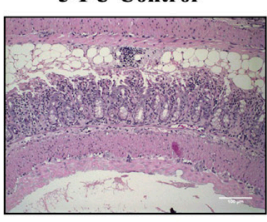

Matrix

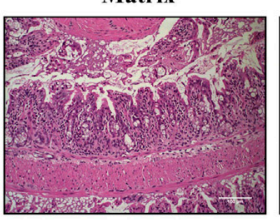

L. Casei BL23

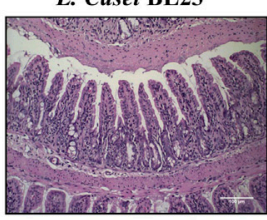

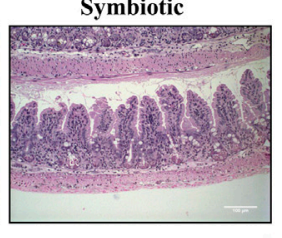

Ileum section of inflamed groups (5-FU-induced Mucositis)

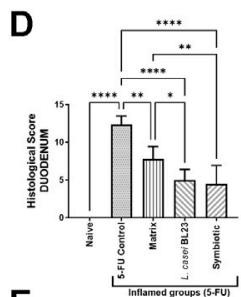

E

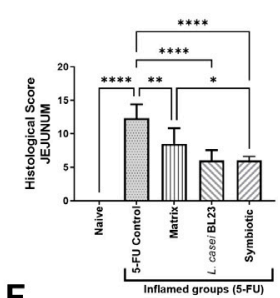

$\mathbf{F}$

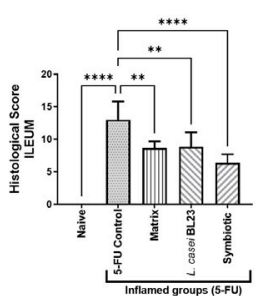

FIGURE 2 | Probiotic lyophilized formulations can reduce inflammation in the duodenal, jejunum, and ileum section of 5-FU-induced mucositis mice. (A, B, C) Photomicrographs of the duodenal, jejunum, and ileum of BALB/c mice, stained in HE, induced or not to mucositis by 5 -FU and those that received the probiotic lyophilized formulations. The animals were gavage with: PBS pH 7.4 (Naive group and 5-FU inflamed control group); 12\% skimmed milk supplemented with 30\% WPI and Fructooligosaccharide (Matrix); a formulation containing L. casei BL23, a formulation containing the mix of probiotics (Symbiotic). The photos show the $\times 20$ magnification. Scale bar $=100 \mu \mathrm{m}$ (D, E, F) Histopathological score of the duodenal, jejunum, and ileum section. Results were expressed as means \pm standard deviation ( $n=6-9$ ). One-way ANOVA and Tukey post-hoc tests were used for multiple comparison. Asterisks represent statistically significant differences as follows: ${ }^{\star} p<0.05$; ${ }^{\star \star} p<0.01 ;{ }^{\star \star \star} p<0.001 ;{ }^{\star \star \star \star} p<0.0001$. 


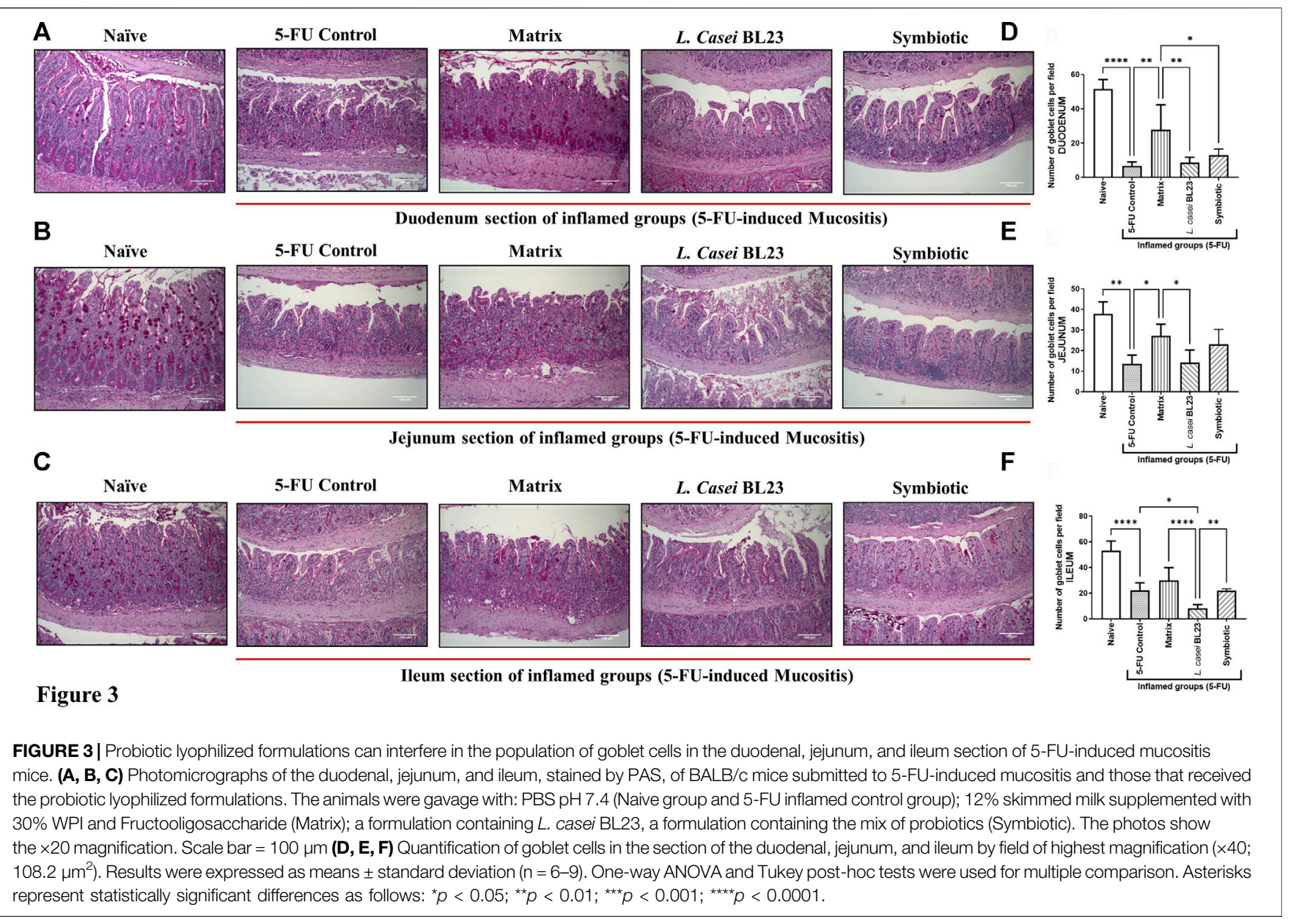

section, respectively. In the Naive group, no morphological change in duodenum, jejunum, and ileum sections was observed according to the parameters analyzed. Sections were devoid of inflammatory infiltrate and the general architecture of the mucosa remained unchanged. In the 5-FU inflamed control group, an increase in the infiltration of inflammatory cells in the lamina propria, submucosa, and muscle layer was observed in duodenum, jejunum, and ileum section. So was an increase in the thickness of the muscle layer, as well as a drastic change in the villi, being partially or completely destroyed. Furthermore, in some animals in the 5-FU inflamed group, the presence of ulceration and erosion was observed (not shown in the images). The group that received the Matrix showed moderate preservation of the architecture and height of the villi, with a partial destruction of the crypts and the presence of a moderate (mixed) inflammatory infiltrate, reaching the mucosa and submucosa. The group that received the $L$. casei BL23 formulation showed moderate mononuclear inflammatory infiltration, moderate to intense destruction of the crypts, and a moderate preservation of the villi architecture and height. In the group that received the Symbiotic formulation, discrete destruction and reduction of villi, moderate inflammatory infiltrate with mucosal and submucosal involvement, with moderate loss of crypts, can be observed. The histopathological score of the duodenum, jejunum, and ileum sections (Figures 2D-F, respectively) shows a reduction in the analyzed parameters with a significant difference between the 5-FU group and the groups treated with the Matrix, L. casei BL23, or Symbiotic ( $p<0.01 ; p<0.001 ; p<0.001$, respectively). In addition, the comparative analysis identified significant differences between the group treated with the Matrix, and the group treated with Symbiotic, for scores in duodenum and jejunum section $(p<$ $0.05 ; p<0.01$, respectively), with a significant reduction of the histopathological score in the latter.

As expected, the 5-FU induced mucositis in this mice model triggers substantial decrease in goblet cells number 6.66, 13.47, 22.30 goblet cell/hpf in duodenum, jejunum, and ileum section, respectively (Figures 3A-C for) when compared to the groups injected with $0.9 \%$ saline, 51.4, 37.9, 52.93 goblet cell/hpf in duodenum, jejunum, and ileum section, respectively. In the other hand, L. casei BL23 and Symbiotic treatment did not prevent the degeneration of goblet cells in the mice duodenum, jejunum, and ileum section. However, only the Matrix was able to significantly reduce the degeneration of goblet cells in the duodenum and jejunum $(27.8,27.2$ goblet cell/hpf, $p<$ $0.05 ; p<0.01$, respectively), not in the ileum. 


\section{Symbiotic Prevents Increase in Gut Permeability}

Intestinal permeability was evaluated after oral gavage of mice with radiolabelled diethylenetriaminepentaacetate $\left({ }^{99 \mathrm{~m}} \mathrm{Tc}\right.$ DTPA), followed by quantification of radioactivity in the animal's blood. As expected, 5-FU injection significantly increased intestinal permeability $(p<0.001)$, compared to the Naive control group (Figure 4). There was no significant difference between the group treated with the L. casei BL23 and the 5-FU control group. However, animals treated with Matrix and Symbiotic exhibited significantly decreased $(p<$ 0.001 ) intestinal permeability, compared to the 5-FU inflamed control group. Furthermore, there was no difference between the Naive, Matrix, and Symbiotic groups. Additionally, when the Matrix and Symbiotic groups were compared to the L. casei BL23 group, a significant reduction in intestinal permeability values was observed $(p<0.05)$.

\section{Symbiotic Increases Expression of Epithelial Barriers Genes}

Among Naïve, 5-FU (inflamed control group), Matrix, and $L$. casei BL23 groups, no difference was found between groups in the expression of genes $z o-1, z o-2$, claudin-1, and occluding (Figure 5). However, the Symbiotic treatment was able to significantly increase the expression of the genes zo-1 $(p<$ $0.01)$, occludin $(p<0.05)$, and claudin-1 $(p<0.05)$, when compared to the 5-FU inflamed control groups. It is noteworthy that expression of the ZO-1 and Occludin genes in the Symbiotic group was significantly higher, when compared to Matrix and L. casei BL23 groups, respectively, zo-1 $(p<0.01 ; p<$ $0.05)$, ocludin $(p<0.05 ; p<0.05)$.

\section{Symbiotic Modulates Anti-Inflammatory Cytokines in Mice lleum}

As shown in Figure 6, the cytokines IL-1 $\beta$, IL-6, IL-17, and TNF$\alpha$ were significantly enhanced $(p<0.001 ; p<0.05 ; p<0.0001 ; p<$ 0.001 , respectively) in the ileum of animals administered with 5 FU (inflamed control group), when compared to the Naïve control group. However, Symbiotic treatment was able to reduce significantly cytokines levels of IL-1 $\beta$, IL-6, IL-17, TNF- $\alpha(p<0.05 ; p<0.0001 ; p<0.0001 ; p<0.001$, respectively) compared to the 5 -FU control group. In addition, the Symbiotic group reduced significantly $(p<0.05)$ the levels of IL-1 $\beta$, when compared to the Matrix group. The Matrix and $L$. casei BL23 treatments were also able to reduce significantly cytokines levels of IL-6, IL-17, and TNF- $\alpha$, compared to the 5FU group. No difference was found in cytokine levels of INF- $\gamma$. Additionally, only L. casei BL23 was able to increase Il-10 levels, compared to the 5-FU inflamed control group $(p<0.05)$.

\section{DISCUSSION}

Mucositis is characterized by inflammation and by cell loss at the level of the epithelial barrier of the digestive tract. This leads to

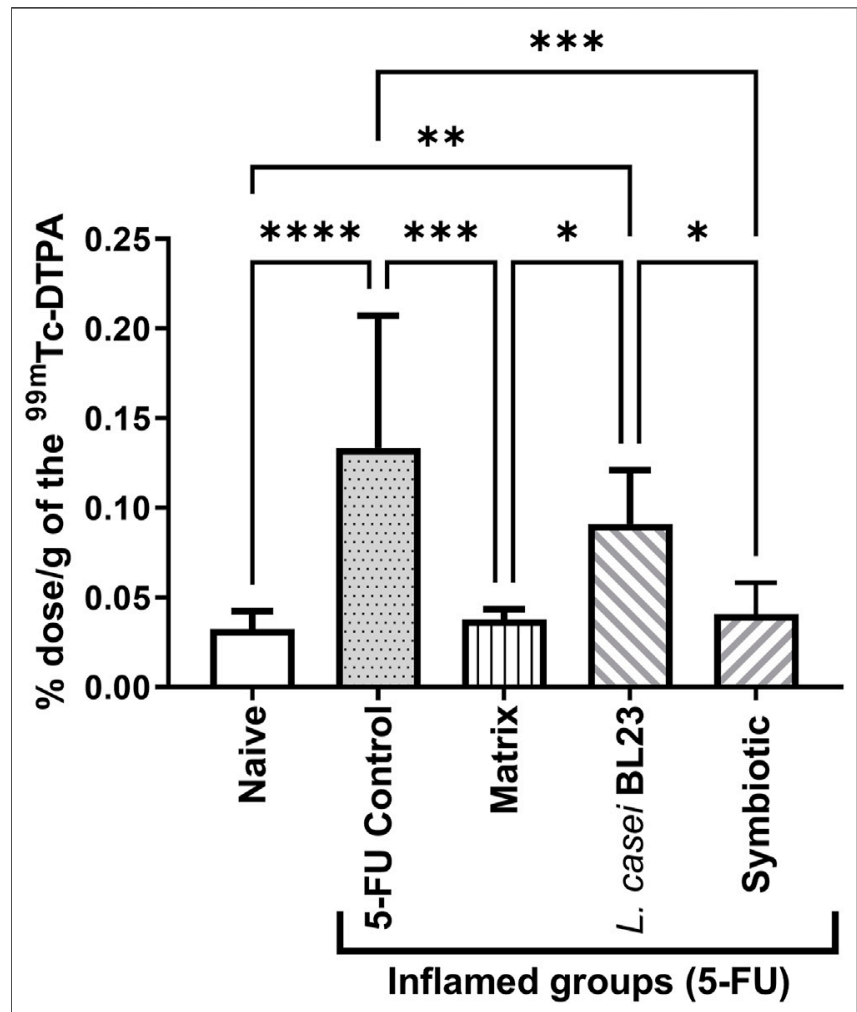

FIGURE 4 | Lyophilized probiotic formulations can decrease intestinal permeability in mice with 5-FU-induced mucositis. Intestinal permeability was measured $72 \mathrm{~h}$ after mucositis induction by determining Technetium-99 m radioactivity (99mTc-DTPA) in mouse blood. The animals were gavage with: PBS pH 7.4 (Naive group and 5-FU inflamed control group); 12\% skimmed milk supplemented with 30\% WPI and Fructooligosaccharide (Matrix); a formulation containing L. casei BL23, a formulation containing the mix of probiotics (Symbiotic). Means and standard deviations were calculated from an independent experiment for each of the 9 animals per group. Asterisks represent statistically significant differences between the strains and were indicated as follows: ${ }^{\star} p<0.05 ;{ }^{* \star} p<0.01 ;{ }^{* \star *} p<0.001$ and ${ }^{\star \star \star *} p<0.0001$.

mucosal lesions and/or ulcerations throughout the TGI, i.e., from the mouth to the anus (Soares et al., 2008). Treatments aimed at controlling such side effects of cancer chemotherapy are lacking. We thus proposed to use probiotic bacterial strains, either in suitable culture media (Do Carmo et al., 2019) or in dairy matrices supplemented with whey protein (Cordeiro et al., 2018). We obtained promising results against adverse effects caused by chemotherapeutics, precisely in 5-FU-induced mucositis. Furthermore, Galdindo and collaborators used a FOS prebiotic to attenuate the effects of 5-FU-induced mucositis and obtained promising results (Galdino et al., 2018). Therefore, the present work aimed to develop a symbiotic product from milk, fermented by strains of Lactobacillus casei BL23, Lactiplantibacillus plantarum B7, and Lacticaseibacillus rhamnosus D1, supplemented with WPI, added with FOS, and subsequently lyophilized, to evaluate its therapeutic effects in a murine model of 5-FU-induced mucositis.

Initially, bioactive compounds analyses showed that the Symbiotic (supplemented with FOS) has high levels of the $\mathrm{DPPH}, \mathrm{ACE}$, a-amylase, and a-glucosidase inhibitor bioactive 

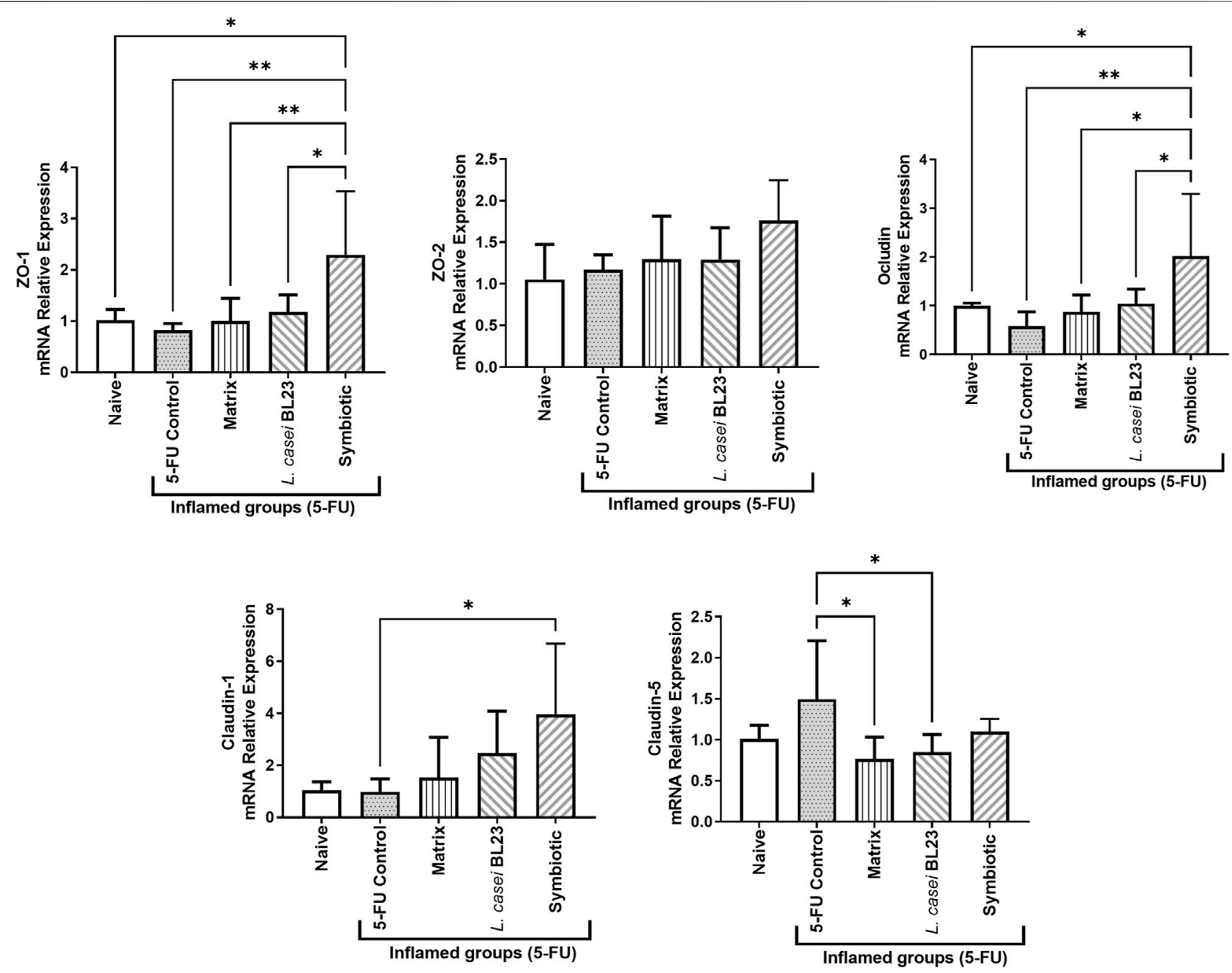

FIGURE 5 | Probiotic lyophilized formulations can modulate gene expression of epithelial barrier genes in the ileum section of mice with 5-FU-induced mucositis. Gene for zonula occludes 1 and 2 (zo-1 and zo-2, respectively), occludin (ocln), and claudin-1 (cln-1) were measured by RT-qPCR. The animals were gavage with: PBS pH 7.4 (Naive group and 5-FU inflamed control group); $12 \%$ skimmed milk supplemented with 30\% WPI and Fructooligosaccharide (Matrix); a formulation containing L. casei BL23, a formulation containing the mix of probiotics (Symbiotic). Means and standard deviations are calculated from 3 animals per group, from 2 independent repetitions and each quantification was performed in duplicate (technical duplicate). Asterisks represent statistically significant differences between strains and were indicated as follows: ${ }^{\star} p<0.05 ;{ }^{* \star} p<0.01 ;{ }^{* \star *} p<0.001$ and ${ }^{* \star \star *} p<0.0001$.

compounds. These inhibitor peptides have beneficial effects in other intestinal inflammations such as diabetes, hypertension, obesity, and inflammatory bowel disease (Takiishi et al., 2017; Salinas et al., 2021). It is worth emphasizing the role of the antioxidant activity, which is: protective against histological damage, apoptotic changes, and proinflammatory cytokines, mainly caused by chemotherapeutic agents. Given the previous selection of bacterial strains due to their probiotic potential in infection in vivo models and mucositis (Acurcio L. B. et al., 2017, Acurcio et al., 2017 LB.; Cordeiro et al., 2018; Valente et al., 2019), and subsequent characterization of the lyophilized fermented product and supplemented with FOS, we decided to investigate its therapeutic potential in a murine model of mucositis induced by 5 -FU chemotherapy.

It is known that the application of 5-Fluorouracil in mice leads to a significant weight loss, when compared to non-inflamed animals (Chang et al., 2012). As seen in previous studies, 5-FUinduced mucositis in $\mathrm{BALB} / \mathrm{c}$ mice triggers a drastic reduction in weight, pasty stools with the presence of blood, as a result of substantial changes in the architecture, and destruction of the intestinal mucosa, resulting in intense inflammatory process (Carvalho RD. et al., 2017; Cordeiro et al., 2018). This also favors a change in intestinal permeability (Galdino et al., 2018; Do Carmo et al., 2019). The probiotic VSL\#3 was tested in a murine model of mucositis (Bowen et al., 2007). Hence, this product, which contains several bacterial strains (one strain of Streptococcus thermophilus, four Lactobacillus spp., and three Bifidobacterium spp.), was effective in reducing weight loss in a mucositis model induced by irinotecan. Since mucositis affects the entire gastrointestinal tract, we decided to extend the histological analysis to include the duodenum and jejunum 

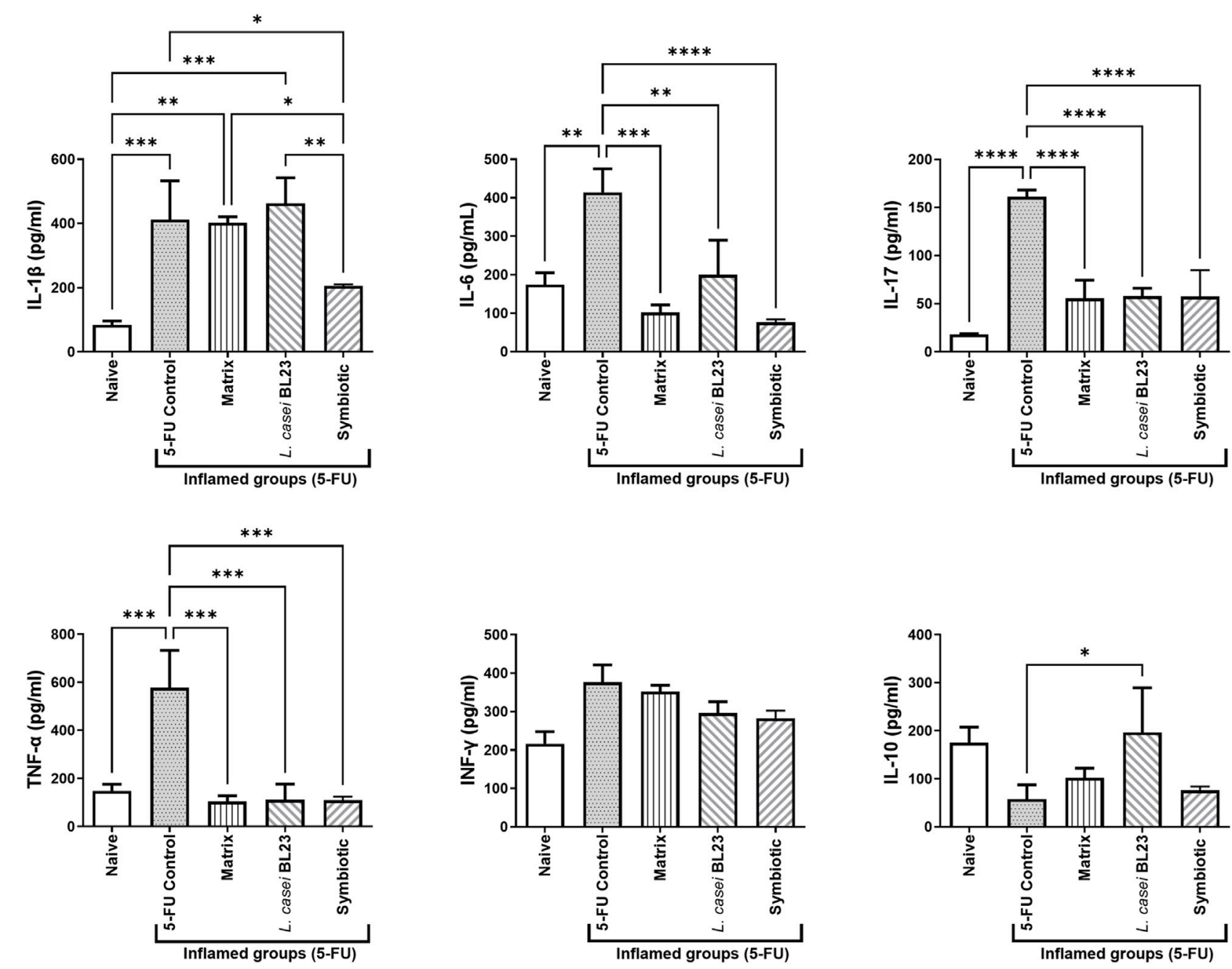

FIGURE 6 | Probiotic lyophilized formulations can modulate cytokine production in the ileum section of mice with 5-FU-induced mucositis. Cytokine levels (A IL-1 $\beta$, IL-6, IL-10, IL-17, TNF- $\alpha$, and INF- $\gamma$ ratio were determined in mouse ileum tissue supernatant by ELISA. The animals were gavaged with: PBS pH 7.4 (Naive group and 5FU inflamed control group); 12\% skimmed milk supplemented with 30\% WPI and Fructooligosaccharide (Matrix); a formulation containing L. casei BL23, a formulation containing the mix of probiotics (Symbiotic). Means and standard deviations are calculated from 3 animals per group, from 3 independent repetitions, and each quantification was performed in triplicate (technical triplicates). Asterisks represent statistically significant differences between strains and were indicated as follows: ${ }^{\star} p<0.05 ;{ }^{\star \star} p<0.01 ;{ }^{\star \star \star} p<0.001$ and ${ }^{\star \star \star \star} p<0.0001$.

section, together with the ileum section, described in the literature as the site intensely affected by 5 -FU action (Touchefeu et al., 2014). In the 5-FU control group, alteration and destruction of the mucosal architecture, as well as extensive inflammation, was observed in the duodenum and jejunum. In the histological analysis of the duodenum, jejunum, and ileum, it was observed that all formulations were able to reduce inflammation in the intestinal mucosa. Interestingly, the Matrix, containing WPI and FOS, was sufficient to reduce inflammation. This result is in agreement with previous studies using WPI and FOS (Cordeiro et al., 2018; Galdino et al., 2018), which indicated significant protection. Other authors suggested that some of the amino acids present in WPI, such as cysteine and glutamate, are used to produce glutathione (Moslehi et al., 2014). This is responsible for providing the main intracellular defense against oxidative stresses, which occurs in severe inflammation such as mucositis, a fact that makes WPI a potential antiinflammatory compound (Shiby and Mishra, 2013). Futhermore, the results found here using our Symbiotic are similar to those found in other works. For example, Yeung et al., using Lactobacillus acidophilus and Bifidobacterium bifidum strains, significantly reduced mucosal damage caused by 5 -FU-induced mucositis in a murine model (Yeung et al., 2015). In the work of Trindade et al., the administration of the symbiotic Simbioflora, which contains four probiotic strains plus FOS, also reduced damages in the same animal model (Trindade et al., 2018). We suggest that the synergy provided by the interaction of the Lactobacillus three strains, with previously tested anti-inflammatory potential, plus FOS, is 
responsible for improving the response to inflammation. However, more studies will be needed to understand the synergistic mechanisms, the specific action of each of the strains, and the mechanism responsible for mitigation of inflammation caused by chemotherapy.

The impact of mucositis, using chemotherapeutics, expands throughout the intestinal barrier, also affecting the production of goblet cells (Carvalho RDO. et al., 2017). The group that received the lyophilization matrix, interestingly, showed a significant preservation of these cells. Perhaps, the matrix components that were not metabolized by the strains helped in the preservation of goblet cells. A hypothesis for this result, as observed by Cordeiro et al. (2018), would be the availability of amino acids via WPI, mainly threonine, cysteine, and serine for the synthesis of this mucus (Faure et al., 2006) and also the presence of FOS action, increasing the population of Bifidobacteria, which would modulate mucus production.

Mucositis alters the epithelial integrity of the gastrointestinal tract. As a result, the intestinal permeability is affected (Cinausero et al., 2017), allowing translocation of harmful and toxic substances produced by pathobionts bacteria. This may in turn allow their passage from the intestinal lumen to the blood circulation, causing unwanted systemic effects that can lead to death (Fine et al., 2020). Accordingly, 5-FU led here to increased intestinal permeability of animals in the inflamed, when compared to the Naive group. Consumption of L. casei BL23 failed to prevent this increase, while preserving the architecture and reducing the inflammation in the small intestine. However, the Matrix and Symbiotic both significantly reduced the intestinal permeability of mucositis mice. In the work of Galdino et al., FOS administration in 5-FU mucositis mice led to similar results (Galdino et al., 2018). In the work of Antunes et al. (2016), the use of the amino acid L-arginine, present in WPI in large quantities, reduced damages to the mucosa and intestinal permeability of animals in a murine model of mucositis. However, synergy with the strains contained here in the Symbiotic promoted an increase in the expression of genes involved in the intestinal epithelial barrier ( $\mathrm{ZO}-1$, Ocludin, and Claudin-1). This may explain how this formulation was able to reduce intestinal permeability.

In response to the administration of the chemotherapeutic agent 5-FU, mediators of the inflammatory response are activated, including the transcription factor NF-kb. Its activation leads to the production of pro-inflammatory cytokines, such as TNF- $\alpha$, IL1- $\beta$, and IL-6 and IL-17 (Chang et al., 2012). These inflammatory markers play a central role in mucositis and are released in the inflammatory phase (LopezCastejon and Brough, 2011). The symbiotic was able to reduce the level of pro-inflammatory cytokines, which allows us to hypothesize that the therapeutic action of this formulation in the 5-FU-induced mucositis model is mediated by the inhibition of the pro-inflammatory response. This modulatory effect may be favored by metabolites (SCFA, bacteriocins, and neurotransmitters such as GABA) as a result of fermentation by the three strains. This would explain the difference between the Matrix and L. casei BL23. However, further experiments will be necessary to fully explain the mechanisms responsible for the healing effect observed here and to identify the different antiinflammatory effectors produced by these strains.

\section{CONCLUSION}

In conclusion, we have demonstrated that the lyophilized Symbiotic formulation, containing WPI, FOS, and fermented by Lactobacillus casei BL23, Lactiplantibacillus plantarum B7 and Lacticaseibacillus rhamnosus B1, has anti-inflammatory potential in 5-FU-induced mucositis, reducing animal weight loss, intestinal permeability, modulating genes implicated in the intestinal epithelial barrier, controlling pro-inflammatory cytokine levels, and reducing mucosal damage caused by chemotherapy. This work opens new perspectives for the development of functional symbiotic products for target populations, in the context of mucositis, based on smart selection of matrices and bacterial consortia.

\section{DATA AVAILABILITY STATEMENT}

The raw data supporting the conclusions of this article will be made available by the authors, without undue reservation.

\section{ETHICS STATEMENT}

The animal study was reviewed and approved by the Ethics Committee on Animal Experimentation of the Federal University of Minas Gerais (379/2018).

\section{AUTHOR CONTRIBUTIONS}

V.A. and F.C. conceived and designed the experiments. L.A. provided strains. J.A. and A.C. performed and analyzed ELISA assays. B.S., A.G., M.Q., B.C., E.O., S.H., G.B., and A.G-G. were major contributors to animal experimentation. J.G., R.S., R.R., M.S., M.F., E.E., and A.G-G. performed centesimal and mineral composition. E.F. performed, analyzed, and interpreted the histological analysis from colon slides. K.V., S.F., and V.C. performed permeability assays. T.D. and G.C. perfomed RT-PCR analyses. V.A. and F.C. wrote the original draft. G.J. and Y.L. gave scientific advice and participated in the writing of the manuscript. All authors contributed to data interpretation, drafting the manuscript, critically revising the manuscript, and approving its final version.

\section{FUNDING}

This work was supported by Fundação de Amparo à Pesquisa do Estado de Minas Gerais (FAPEMIG), Conselho Nacional de Desenvolvimento Científico e Tecnológico (CNPq 151533/ 2018-0), and Coordenação de Aperfeiçoamento de Pessoal de Nível Superior (CAPES). 


\section{REFERENCES}

Acurcio, L. B., Sandes, S. H. C., Bastos, R. W., Sant'anna, F. M., Pedroso, S. H. S. P., Reis, D. C., et al. (2017b). Milk Fermented by Lactobacillus Species from Brazilian Artisanal Cheese Protect Germ-Free-Mice Against Salmonella Typhimurium Infection. Benef. Microbes 8, 579-588. doi:10.3920/ BM2016.0163

Acurcio, L. B., Bastos, R. W., Sandes, S. H. d. C., Guimarães, A. C. d. C., Alves, C. G., Reis, D. C. d., et al. (2017a). Protective Effects of Milk Fermented by Lactobacillus Plantarum B7 from Brazilian Artisanal Cheese on a Salmonella Enterica Serovar Typhimurium Infection in BALB/c Mice. J. Funct. Foods 33, 436-445. doi:10.1016/j.jff.2017.04.010

Antunes, M. M., Leocádio, P. C., Teixeira, L. G., Leonel, A. J., Cara, D. C., Menezes, G. B., et al. (2016). Pretreatment with L-Citrulline Positively Affects the Mucosal Architecture and Permeability of the Small Intestine in a Murine Mucositis Model. JPEN J. Parenter. Enteral Nutr. 40, 279-286. doi:10.1177/ 0148607114567508

Bastos, R. W., Pedroso, S. H., Vieira, A. T., Moreira, L. M., França, C. S., Cartelle, C. T., et al. (2016). Saccharomyces Cerevisiae UFMG A-905 Treatment Reduces Intestinal Damage in a Murine Model of Irinotecan-Induced Mucositis. Benef. Microbes 7, 549-557. doi:10.3920/BM2015.0190

Bowen, J. M., Stringer, A. M., Gibson, R. J., Yeoh, A. S., Hannam, S., and Keefe, D. M. (2007). VSL\#3 Probiotic Treatment Reduces Chemotherapy-Induced Diarrhea and Weight Loss. Cancer Biol. Ther. 6, 1449-1454. doi:10.4161/ cbt.6.9.4622

BRASIL (2006). Ministério da Agricultura, Pecuária e Abastecimento. Instrução Normativa $n^{\circ} 68$ de 12/12/2006. Métodos Análiticos Oficiais Físico-Químicos para controle de leite e produtos lácteos. Minist. Agric. PECUÁRIA E Abast, 0-49. Available at: https://wp.ufpel.edu.br/inspleite/files/2016/03/Instruçãonormativa-n ${ }^{\circ}$-68-de-12-dezembro-de-2006.pdf. (Accessed September 30, 2020).

Carvalho, R. D., Breyner, N., Menezes-Garcia, Z., Rodrigues, N. M., Lemos, L., Maioli, T. U., et al. (2017a). Secretion of Biologically Active PancreatitisAssociated Protein I (PAP) by Genetically Modified Dairy Lactococcus Lactis NZ9000 in the Prevention of Intestinal Mucositis. Microb. Cel Fact 16, 27. doi:10.1186/s12934-017-0624-x

Carvalho, R. D. O., do Carmo, F. L. R., de Oliveira Junior, A., Langella, P., Chatel, J. M., Bermúdez-Humarán, L. G., et al. (2017b). Use of Wild Type or Recombinant Lactic Acid Bacteria as an Alternative Treatment for Gastrointestinal Inflammatory Diseases: A Focus on Inflammatory Bowel Diseases and Mucositis. Front. Microbiol. 8, 800. doi:10.3389/ fmicb.2017.00800

Chang, C. T., Ho, T. Y., Lin, H., Liang, J. A., Huang, H. C., Li, C. C., et al. (2012). 5Fluorouracil Induced Intestinal Mucositis via Nuclear Factor-Kb Activation by Transcriptomic Analysis and In Vivo Bioluminescence Imaging. PLoS ONE 7, e31808. doi:10.1371/journal.pone. 0031808

Cinausero, M., Aprile, G., Ermacora, P., Basile, D., Vitale, M. G., Fanotto, V., et al. (2017). New Frontiers in the Pathobiology and Treatment of Cancer RegimenRelated Mucosal Injury. Front. Pharmacol. 8, 354. doi:10.3389/fphar.2017.00354

Ciorba, M., Hellemeier, C., Stenson, W., and Parikh, P. (2016). Probiotics to Prenvents Gastrointestinal Toxicity from Cancer Therapy: An Interpretative Riview Ans Call to Action. Curr. Opin. Support. Palliat. Care 1848, 3047-3054. doi:10.1016/j.bbamem.2015.02.010.Cationic

Cordeiro, B. F., Alves, J. L., Belo, G. A., Oliveira, E. R., Braga, M. P., da Silva, S. H., et al. (2021). Therapeutic Effects of Probiotic Minas Frescal Cheese on the Attenuation of Ulcerative Colitis in a Murine Model. Front. Microbiol. 12, 623920. doi:10.3389/fmicb.2021.623920

Cordeiro, B. F., Oliveira, E. R., da Silva, S. H., Savassi, B. M., Acurcio, L. B., Lemos, L., et al. (2018). Whey Protein Isolate-Supplemented Beverage, Fermented by Lactobacillus Casei BL23 and Propionibacterium Freudenreichii 138, in the Prevention of Mucositis in Mice. Front. Microbiol. 9, 2035. doi:10.3389/ fmicb.2018.02035

de Barros, P. A. V., Rabelo Andrade, M. E., de Vasconcelos Generoso, S., Mendes Miranda, S. E., Dos Reis, D. C., Lacerda Leocádio, P. C., et al. (2018). Conjugated Linoleic Acid Prevents Damage Caused by Intestinal Mucositis Induced by 5-Fluorouracil in an Experimental Model. Biomed. Pharmacother. 103, 1567-1576. doi:10.1016/j.biopha.2018.04.133
Diehl, K. H., Hull, R., Morton, D., Pfister, R., Rabemampianina, Y., Smith, D., et al. (2001). A Good Practice Guide to the Administration of Substances and Removal of Blood, Including Routes and Volumes. J. Appl. Toxicol. 21, 15-23. doi:10.1002/jat.727

Do Carmo, F. L. R., Rabah, H., Cordeiro, B. F., Da Silva, S. H., Pessoa, R. M., Fernandes, S. O. A., et al. (2019). Probiotic Propionibacterium Freudenreichii Requires SlpB Protein to Mitigate Mucositis Induced by Chemotherapy. Oncotarget 10, 7198-7219. doi:10.18632/oncotarget.27319

Eales, J., Gibson, P., Whorwell, P., Kellow, J., Yellowlees, A., Perry, R. H., et al. (2017). Systematic Review and Meta-Analysis: The Effects of Fermented Milk with Bifidobacterium Lactis CNCM I-2494 and Lactic Acid Bacteria on Gastrointestinal Discomfort in the General Adult Population. Therap Adv. Gastroenterol. 10, 74-88. doi:10.1177/1756283X16670075

Faure, M., Mettraux, C., Moennoz, D., Godin, J. P., Vuichoud, J., Rochat, F., et al. (2006). Specific Amino Acids Increase Mucin Synthesis and Microbiota in Dextran Sulfate Sodium-Treated Rats. J. Nutr. 136, 1558-1564. doi:10.1093/jn/ 136.6.1558

Fine, R. L., Manfredo Vieira, S., Gilmore, M. S., and Kriegel, M. A. (2020). Mechanisms and Consequences of Gut Commensal Translocation in Chronic Diseases. Gut Microbes 11, 217-230. doi:10.1080/ 19490976.2019.1629236

Flesch, A. G. T., Poziomyck, A. K., and Damin, D. D. C. (2014). The Therapeutic Use of Symbiotics. Arq. Bras. Cir. Dig. ABCD Braz. Arch. Dig. Surg. 27, 206-209. doi:10.1590/S0102-67202014000300012

Galdino, F. M. P., Andrade, M. E. R., Barros, P. A. V. D., Generoso, S. D. V., Alvarez-Leite, J. I., Almeida-Leite, C. M. D., et al. (2018). Pretreatment and Treatment with Fructo-Oligosaccharides Attenuate Intestinal Mucositis Induced by 5-FU in Mice. J. Funct. Foods 49, 485-492. doi:10.1016/ j.jff.2018.09.012

Grom, L. C., Rocha, R. S., Balthazar, C. F., Guimarães, J. T., Coutinho, N. M., Barros, C. P., et al. (2020). Postprandial Glycemia in Healthy Subjects: Which Probiotic Dairy Food Is More Adequate? J. Dairy Sci. 103, 1110-1119. doi:10.3168/jds.2019-17401

Ishikawa, H., Akedo, I., Otani, T., Suzuki, T., Nakamura, T., Takeyama, I., et al. (2005). Randomized Trial of Dietary Fiber and Lactobacillus Casei Administration for Prevention of Colorectal Tumors. Int. J. Cancer 116, 762-767. doi:10.1002/ijc. 21115

Justino, P. F., Melo, L. F., Nogueira, A. F., Morais, C. M., Mendes, W. O., Franco, A. X., et al. (2015). Regulatory Role of Lactobacillus Acidophilus on Inflammation and Gastric Dysmotility in Intestinal Mucositis Induced by 5-Fluorouracil in Mice. Cancer Chemother. Pharmacol. 75, 559-567. doi:10.1007/s00280-014-2663-x

Konrad, B., Anna, D., Marek, S., Marta, P., Aleksandra, Z., and Józefa, C. (2014). The Evaluation of Dipeptidyl Peptidase (DPP)-IV, $\alpha$-Glucosidase and Angiotensin Converting Enzyme (ACE) Inhibitory Activities of Whey Proteins Hydrolyzed with Serine Protease Isolated from Asian Pumpkin (Cucurbita Ficifolia). Int. J. Pept. Res. Ther. 20, 483-491. doi:10.1007/ s10989-014-9413-0

Lee, N.-K., Jeewanthi, R. K. C., Park, E.-H., and Paik, H.-D. (2016). Short Communication: Physicochemical and Antioxidant Properties of CheddarType Cheese Fortified with Inula Britannica Extract. J. Dairy Sci. 99, 83-88. doi:10.3168/jds.2015-9935

Lopez-Castejon, G., and Brough, D. (2011). Understanding the Mechanism of IL$1 \beta$ Secretion. Cytokine Growth Factor. Rev. 22, 189-195. doi:10.1016/ j.cytogfr.2011.10.001

Moslehi, A., Taghizadeh-Ghehi, M., Gholami, K., Hadjibabaie, M., JahangardRafsanjani, Z., Sarayani, A., et al. (2014). N-acetyl Cysteine for Prevention of Oral Mucositis in Hematopoietic SCT: A Double-Blind, Randomized, PlaceboControlled Trial. Bone Marrow Transpl. 49, 818-823. doi:10.1038/bmt.2014.34

Picó-Monllor, J. A., and Mingot-Ascencao, J. M. (2019). Search and Selection of Probiotics that Improve Mucositis Symptoms in Oncologic Patients. A Systematic Review. Nutrients 11, 2322. doi:10.3390/nu11102322

Prisciandaro, L. D., Geier, M. S., Butler, R. N., Cummins, A. G., and Howarth, G. S. (2011). Probiotic Factors Partially Improve Parameters of 5-FluorouracilInduced Intestinal Mucositis in Rats. Cancer Biol. Ther. 11, 671-677. doi:10.4161/cbt.11.7.14896

Raizel, R., Santini, E., Kopper, A. M., and Filhodos, A. D. R. (2011). Efeitos Do consumo de probióticos, prebióticos e simbióticos para o organismo humano. Ciênc. Saúde 4, 66-74. doi:10.15448/1983-652X.2011.2.8352 
Rodríguez-Caballero, A., Torres-Lagares, D., Robles-García, M., Pachón-Ibáñez, J., González-Padilla, D., and Gutiérrez-Pérez, J. L. (2012). Cancer TreatmentInduced Oral Mucositis: A Critical Review. Int. J. Oral Maxillofac. Surg. 41, 225-238. doi:10.1016/j.ijom.2011.10.011

Salinas, E., Reyes-Pavón, D., Cortes-Perez, N. G., Torres-Maravilla, E., BitzerQuintero, O. K., Langella, P., et al. (2021). Bioactive Compounds in Food as a Current Therapeutic Approach to Maintain a Healthy Intestinal Epithelium. Microorganisms 9, 1634. doi:10.3390/microorganisms 9081634

Santos, L. A. A., Dorna, M. d. S., Vulcano, D. S. B., Augusti, L., Franzoni, L. d. C., Gondo, F. F., et al. (2015). Terapia nutricional nas doenças inflamatórias intestinais: artigo de revisão. Nutrire 40, 383-396. doi:10.4322/2316-7874.56714

Shiby, V. K., and Mishra, H. N. (2013). Fermented Milks and Milk Products as Functional Foods-Aa Review. Crit. Rev. Food Sci. Nutr. 53, 482-496. doi:10.1080/10408398.2010.547398

Shu, Z., Li, P., Yu, B., Huang, S., and Chen, Y. (2020). The Effectiveness of Probiotics in Prevention and Treatment of Cancer Therapy-Induced Oral Mucositis: A Systematic Review and Meta-Analysis. Oral Oncol. 102, 104559. doi:10.1016/j.oraloncology.2019.104559

Soares, P. M., Mota, J. M., Gomes, A. S., Oliveira, R. B., Assreuy, A. M., Brito, G. A., et al. (2008). Gastrointestinal Dysmotility in 5-Fluorouracil-Induced Intestinal Mucositis Outlasts Inflammatory Process Resolution. Cancer Chemother. Pharmacol. 63, 91-98. doi:10.1007/s00280-008-0715-9

Sonis, S. T. (2004). A Biological Approach to Mucositis. J. Support. Oncol. 2, 21-26.

Stringer, A. M. (2013). Interaction between Host Cells and Microbes in ChemotherapyInduced Mucositis. Nutrients 5, 1488-1499. doi:10.3390/nu5051488

Takiishi, T., Fenero, C. I. M., and Câmara, N. O. S. (2017). Intestinal Barrier and Gut Microbiota: Shaping Our Immune Responses throughout Life. Tissue Barriers 5, e1373208. doi:10.1080/21688370.2017.1373208

Tang, Y., Wu, Y., Huang, Z., Dong, W., Deng, Y., Wang, F., et al. (2017). Administration of Probiotic Mixture DM\#1 Ameliorated 5-Fluorouracil-Induced Intestinal Mucositis and Dysbiosis in Rats. Nutrition 33, 96-104. doi:10.1016/j.nut.2016.05.003

Touchefeu, Y., Montassier, E., Nieman, K., Gastinne, T., Potel, G., Bruley des Varannes, S., et al. (2014). Systematic Review: the Role of the Gut Microbiota in Chemotherapy- or Radiation-Induced Gastrointestinal Mucositis - Current Evidence and Potential Clinical Applications. Aliment. Pharmacol. Ther. 40, 409-421. doi:10.1111/apt.12878

Trindade, L. M., Martins, V. D., Rodrigues, N. M., Souza, E. L. S., Martins, F. S., Costa, G. M. F., et al. (2018). Oral Administration of Simbioflora ${ }^{\circledR}$ (Synbiotic)
Attenuates Intestinal Damage in a Mouse Model of 5-Fluorouracil-Induced Mucositis. Benef. Microbes 9, 477-486. doi:10.3920/BM2017.0082

Valente, G. L. C., Acurcio, L. B., Freitas, L. P. V., Nicoli, J. R., Silva, A. M., Souza, M. R., et al. (2019). Short Communication: In Vitro and In Vivo Probiotic Potential of Lactobacillus Plantarum B7 and Lactobacillus Rhamnosus D1 Isolated from Minas Artisanal Cheese. J. Dairy Sci. 102, 5957-5961. doi:10.3168/jds.201815938

van der Velden, W. J., Herbers, A. H., Netea, M. G., and Blijlevens, N. M. (2014). Mucosal Barrier Injury, Fever and Infection in Neutropenic Patients with Cancer: Introducing the Paradigm Febrile Mucositis. Br. J. Haematol. 167, 441-452. doi:10.1111/bjh.13113

Yeung, C. Y., Chan, W. T., Jiang, C. B., Cheng, M. L., Liu, C. Y., Chang, S. W., et al. (2015). Amelioration of Chemotherapy-Induced Intestinal Mucositis by Orally Administered Probiotics in a Mouse Model. PLOS ONE 10, e0138746. doi:10.1371/journal.pone.0138746

Conflict of Interest: The authors declare that the research was conducted in the absence of any commercial or financial relationships that could be construed as a potential conflict of interest.

The handling editor declared a past co-authorship with one of the authors VADCA.

Publisher's Note: All claims expressed in this article are solely those of the authors and do not necessarily represent those of their affiliated organizations, or those of the publisher, the editors, and the reviewers. Any product that may be evaluated in this article, or claim that may be made by its manufacturer, is not guaranteed or endorsed by the publisher.

Copyright (c) 2021 Savassi, Cordeiro, Silva, Oliveira, Belo, Figueiroa, Alves Queiroz, Faria, Alves, Silva, Campos, Esmerino, Rocha, Freitas, Silva, Cruz, Vital, Fernandes, Cardoso, Acurcio, Jan, Le Loir, Gala-Garcia, do Carmo and Azevedo. This is an open-access article distributed under the terms of the Creative Commons Attribution License (CC BY). The use, distribution or reproduction in other forums is permitted, provided the original author(s) and the copyright owner(s) are credited and that the original publication in this journal is cited, in accordance with accepted academic practice. No use, distribution or reproduction is permitted which does not comply with these terms. 